\title{
Genetic variability for Seed Viability, Seedling Vigor and Cytotoxic Compound Accumulation in Groundnut (Arachis hypogaea L.) upon Accelerated Ageing
}

\author{
M.R. Namratha ${ }^{1 *}$, C.T. Bharath Prasad ${ }^{2}$, Hajira Khanm ${ }^{1}$ and B. Mohan Raju ${ }^{1}$ \\ ${ }^{1}$ Department of Crop Physiology, ${ }^{2}$ Department of Plant Biotechnology, University of \\ Agricultural Sciences, GKVK, Bangalore, Karnataka, India \\ *Corresponding author
}

\section{Keywords \\ Accelerate ageing, Seed viability, Seedling vigor index, Cytotoxic compound \\ Article Info \\ Accepted: \\ 15 January 2019 \\ Available Online: \\ 10 February 2019}

\section{A B S T R A C T}

Groundnut being one of the important oilseed crops rapidly deteriorates during storage due to accumulation of cytotoxic compounds leading to loss of viability and seedling vigor. Although seeds deteriorate naturally during storage, the time taken for complete deterioration process is longer. Globally, researchers employed accelerated ageing method efficiently to screen large number of genotypes to assess the genetic variability for cellular tolerance. In our study, accelerated ageing technique was standardized by exposing the seeds to different incubation time and found $45^{\circ} \mathrm{C}$ for 6 days maintaining $100 \% \mathrm{RH}$ as challenging incubation period for groundnut. However, drastic reduction in seed germination was observed as the incubation period increases and the trend was similar for seed viability and seedling vigor index. Later, genetic variability for seed viability, vigor and accumulation of cytotoxic compounds was examined across groundnut genotypes upon ageing. Further, the correlation study suggest, inverse relationship between cytotoxic compounds and seed viability, germination and seedling vigor index. Accordingly, some of the genotypes namely, KCG6 and ICGV9114 were found to be susceptible to aging treatment, showing reduced seed viability, poor germination with higher accumulation of cytotoxic compounds compared to tolerant genotypes like SB3 and SB15 which showed longer seed viability that accumulated less cytotoxic compounds. Further, gene analysis of some of downstream target shows its relevance in enhancing seed viability.

\section{Introduction}

Groundnut (Arachis hypogaea L.) is one of the world's most important leguminous crops and an economically important oilseed crop which provides high quality edible oil (48$50 \%)$ and easily digestible protein (26-28\%). For the crop establishment in the field, viable seeds are crucial input. Good quality seeds of improved varieties can contribute to about 20$25 \%$ increase in productivity (McDonald, 1999). Therefore, there is a need to sustain seed viability during storage and improve the seedling vigor. But seed viability is a major constraint in groundnut which lasts only for few months (Sung et al., 1994) and 
considered to be one of the most difficult challenges to maintain.

Seed viability controlled by multiple factors such as biotic and abiotic stresses, mechanical damage as well as physiological conditions. Seed moisture content (MC), temperature, relative humidity forms the major determining factor (Ellis et al., 1992). Groundnut seeds can be safely dried to very low levels of MC of 2-6\% above which enhance the deterioration process (Roberts and Ellis, 1989).

Seed deterioration is an irreversible, degenerative natural process that occurs during the ageing process or under adverse environmental conditions. The deterioration of seeds during dry storage is a complex phenomenon involving changes in many seed components which accounts for $100 \%$ loss in seed vigour (Bewley and Black, 1994). Researcher over a last couple of decades showed as seed deteriorates during storage lead to the production of reactive oxygen species (ROS) and reactive carbonyl compounds (RCCs) (Foyer et al., 2003). Seeds during storage are like any other dry desiccating tissue and hence expected to produce significant amount of reactive oxygen species and RCCs via lipid peroxidation and also through glycation which are highly toxic and cause damage to proteins, lipids, carbohydrates and DNA resulting in cell death (Wilson and McDonald, 1986).

These cytotoxic compounds accounts for several physiological and biochemical processes (Priestly et al., 1986), which incidentally have adverse effect on crop establishment. Lipid peroxidation on seems to be the most important reason for early loss of seed viability. Apart from high temperature and relative humidity which control seed moisture content, several other environmental stresses directly or indirectly hasten up the lipid peroxidation process leading to early loss of seed viability (Wilson and McDonald, 1986).

Deterioration of seeds during storage also includes loss in protein integrity which is often described as factors that determine seed longevity. The accumulation of spontaneously damaged proteins (isoaspartyl residues) in seeds due to ageing / stress/ storage often adversely affects the seed vigour and viability (Verma et al., 2013). Further, oxidative damage to DNA, formation of sugar-protein adducts cell membrane degradation, fatty acid oxidation also occur during seed deteriorated. And also, there is encountered decline in the activity of numerous enzymes and decrease in the level of antioxidants such as superoxide dismutase (SOD), ascorbate peroxidase (APX), catalase (CAT), glutathione peroxidase (GPX) and Heat Shock Proteins (HSPs) and other stress related proteins (Asada, 2006). However, in spite of several scavenging mechanisms, a small fraction of ROS escape from the scavenging systems will oxidize surrounding molecules (Bailly et al., 2011). Carbohydrates and lipids targeted by ROS increases the amount of RCCs such as melondialdehyde (MDA), methyl glyoxal (MG), 3-deoxy glucosone (3-DG) are highly cytotoxic leading to production of Amadori products (Mano et al., 2012) ultimately leads to production of Advanced Glycation Endproducts (AGEs) and Advanced Lipoxidation End products (ALEs) (Yin et al., 2009). Many of these carbonyl compounds are found to be active in dry system and play an important role in deterioration of seeds.

From this context, in the present investigation, an attempt was made to(1) assess the genotypic variability for seed viability across the groundnut genotypes (2) study the relevance of cytotoxic compounds on seed viability and seedling vigor 


\section{Materials and Methods}

Plant material and standardization of challenging incubation period for accelerated ageing

Twenty groundnut genotypes namely SB1, SB2, SB3, SB7, SB8, SB10, SB11, SB12, SB13, SB14, SB15, SB16, SB17, SB21, VBT1, VBT3, VBT4, VBT11, ICGV9114 and KCG6 harvested at the same season were obtained from ARS, chintamani used for the present study. Initially, accelerated ageing (AA) technique was standardized by exposing the groundnut seeds to $45{ }^{\circ} \mathrm{C}$ and $100 \%$ relative humidity $(\mathrm{RH})$ for different duration. Later, it was assessed for seed viability, germination, seedling vigor index (SVI) and cytotoxic compound accumulation. For all experiments, three replications were maintained for each treatment and each replicate constituted of 10 seeds. Dry seeds of groundnut genotypes were subjected to a standardized accelerated ageing treatment of $45{ }^{\circ} \mathrm{C}$ with $100 \%$ relative humidity for 6 days. The uniform sized seeds were selected and placed in small paper cover. Seeds in paper covers were placed inside desiccators with water to maintain $100 \% \mathrm{RH}$ and were kept inside incubator (Delouche and Baskin, 1973). After 6 days of incubation, seeds were removed from the desiccators and exposed to normal room temperature and $\mathrm{RH}$ overnight. Respective control seeds were maintained in normal room temperature. These seeds were then used for assessing the seed viability, germination and for quantification of cytotoxic compound

Assessing genetic variability for seed viability, germination per cent and seedling vigor index (SVI) across the groundnut genotypes upon ageing treatment

Measurement of TTC (Tetrazolium chloride) test for seed viability was adopted. Seeds of both control and aged treatment were preconditioned by soaking in distilled water at 28 ${ }^{\circ} \mathrm{C}$ for $4 \mathrm{~h}$ and transferred them in $1 \%$ tetrazolium chloride solution for $6 \mathrm{~h}$ at room temperature in dark, and then washed several times with distilled water to remove excess solution. Two hundred $\mathrm{mg}$ of embryos collected and incubated in TTC solution was ground in $1 \mathrm{ml}$ of SDS and centrifuged at $8,000 \mathrm{rpm}$ for $20 \mathrm{~min}$. Later, the supernatant was collected and the extent of colour development was assessed based on OD values at $485 \mathrm{~nm}$ in spectrophotometer. Some amount of seeds removed from the accelerated ageing treatment and from control conditions were imbibed for $4 \mathrm{~h}$ and then placed in petri plates with moistened blotting paper. After two days, the percent seed germination was measured was arrived as Germination percentage $=($ Number of seeds germinated/ Number of seeds taken) x 100. In order to assess seedling vigour index (SVI), seedlings were maintained in petriplates for 5 more days and end of which, the root length as well as shoot length were measured and with the data of seed germination, the seedling vigor index was determined and compared with the seedlings of control treatment. SVI $=$ Germination percentage $\mathrm{x}$ (root length + shoot length) (Abdul-Baki and Anderson, 1973).

Assessment of cytotoxic compounds across groundnut genotypes upon ageing treatment

\section{Estimation of Melondialdehyde (MDA)}

Excised embryos of about 100 milligram from ageing treatment and control was homogenized in $5 \mathrm{ml}$ of $10 \%$ (W/V) trichloroacetic acid (HiMedia, Nasik, Maharashtra) and $0.25 \%$ of thiobarbutiric acid. The homogenate was centrifuged at $12,000 \mathrm{rpm}$ for $15 \mathrm{~min}$ at room temperature. The supernatant was mixed with an equal 
amount of thiobarbutiric acid $[0.5 \%$ in $20 \%$ (W/V) trichloroacetic acid] (Sigma aldrich, Bangalore, India) and the mixture was boiled for $25 \mathrm{~min}$ at $100{ }^{\circ} \mathrm{C}$ followed by centrifugation for $5 \mathrm{~min}$ at $7,500 \mathrm{rpm}$ to clarify the solution. Absorbance of the supernatant was measured at $532 \mathrm{~nm}$ and 600 $\mathrm{nm}$ and corrected for nonspecific turbidity by subtracting the absorbance at A600. The standard MDA (Sigma Aldrich, Bangalore, India) was used to develop the standard graph.

\section{Estimation of Methyl glyoxal (MG)}

MG was quantified in aged and control embryos according to Yadav et al., (2005). One hundred $\mathrm{mg}$ of tissue was taken and ground in a known volume of distilled water and centrifuged at $11,000 \mathrm{rpm}$ for $10 \mathrm{~min}$ at 40C and supernatant was collected. To quantify the MG content, $250 \mu \mathrm{l}$ of $7.2 \mathrm{mM}$ of 1, 2-diamino benzene (1,2phenylenediamine), $100 \mu \mathrm{l}$ of $5 \mathrm{M}$ perchloric acid and $650 \mu \mathrm{l}$ of the neutralized supernatant were added. The absorbance was read at 336 nm using spectrophotometer (Spectra max plus-384, Spinco Biotech pvt. Ltd., Bangalore).

\section{Estimation of Amadori products}

100 milligram sembryos of both control and aged seeds were ground in $1.2 \mathrm{ml}$ of $50 \mathrm{mM}$ phosphate buffer ( $\mathrm{pH}$ 7.2). The homogenate was vortexed and centrifuged at 12,000 rpm for $15 \mathrm{~min}$. Further, ammonium sulphate of $0.5 \mathrm{~g} \mathrm{ml}-1$ was added to precipitate the proteins. The pellet was dissolved in $3.3 \mathrm{ml}$ phosphate buffer (50 mM, pH 7.2). Extracted proteins were used to measure the Amadori reaction products. The Amadori reaction products were measured using the nitro-blue tetrazolium (NBT) method (Wettlaufer and Leopold, 1991). To this, $1 \mathrm{ml}$ of NBT reagent (0.5 mM NBT in $100 \mathrm{mM}$ sodium carbonate,
$\mathrm{pH} 10.3$ ) was added to $0.2 \mathrm{mg}$ of extracted proteins and incubated at $40^{\circ} \mathrm{C}$ in a water bath. The absorbance at $550 \mathrm{~nm}$ was recorded after 10 and $20 \mathrm{~min}$ of incubation using spectrophotometer.

\section{Expression analysis}

Expression of downstream target genes such as Aldehyde reductase, Aldo-keto reductases 1 catalase, LEA4, heat shock protein 80 (HSP80) and Protein L-iso-aspartyl methyl transferase 1 (PIMT1) were studied in contrasting genotypes after 6 days of accelerated ageing treatment. Total RNA was extracted in embryo using phenol-chloroform method according to Datta et al., (1989), and cDNA was synthesized by oligo(dT) primers using Moloney murine leukaemia virus reverse transcriptase (MMLV-RT; MBI Fermentas, Hanover, MD). The cDNA pool was used as a template to perform RT-PCR analysis. The quantitative real-time RT-PCR was performed with the fluorescent dye SYBR Green (TAKARA SYBR Green qPCR Kit) following the manufacturer's protocol (Opticon 2; MJ research, USA \& MJ Bioworks, Inc). The relative expression levels of the selected genes under a given stress condition were calculated using comparative threshold method. Tubulin was used as internal control for normalization.

\section{Statistical analysis}

Data recorded for different parameter under study were statistically analyzed by using analysis of variance (ANOVA).

\section{Results and Discussion}

The experiment data was recorded and the challenging incubation period for seed viability, seed germination and SVI upon accelerating ageing was standardized in different durations maintaining $45^{\circ} \mathrm{C}$ and 
$100 \%$ RH. Increase in days of incubation decelerates the seed viability (Fig. 1). There was significant decrease in seed germination from 100 to $20 \%$ as time of incubation increases from 2 to 10 days (Fig. 1). There was drastic reduction seed germination after 6 days of incubation period and the trend was similar for seed viability (reduction in TTC) and SVI (Fig. 1a, 1b and 1c). Based on the above data, $45^{\circ} \mathrm{C}$ for 6 days maintaining $100 \% \mathrm{RH}$ was considered as a challenging incubation period for groundnut seed as there were approximately $73 \%$ and $70 \%$ reduction in seed germination and SVI, respectively. Further influence of accelerating ageing across the groundnut genotype for seed germination, viability and SVI was evaluated. Seeds deteriorate during the periods of prolonged storage, but the speed of deterioration varies greatly among species (Priestley, 1986). Therefore, accelerated ageing treatment has been found effective to induce faster deterioration of seeds leading to loss of early seed viability.

The data pertaining showed the effect of ageing on seed viability, germination and SVI in twenty groundnut genotypes are depicted in Table 1. It was exhibited clearly that seed viability, germination and SVI are highly sensitive to ageing treatment and the degree of sensitivity varied greatly among the genotypes (Table 1). There was up to $60 \%$ reduction in TTC on ageing treatment (Table 1). Amongst the genotype, SB3 showed higher seed germination (80\%) compared ICG9114 (67\%) and KCG $6(63 \%)$ which showed lowest seed germination (Table 1). It appears that genotype KCG6 and ICGV9114 were highly susceptible for ageing treatment and lose viability when seed storage condition is altered even to a less extent. Similarly, ageing treatment effect SVI (Table 1). Accordingly, some of the genotypes such as KCG6, ICGV9114, SB1, SB15, SB16 and SB17 showed least SVI upon ageing treatment compared to SB13. The low vigour was due to less or failure of seed germination in those species. Remaining genotype shows intermediate character. It was also observed that, the genotypes which least reduction in TTC showed better seed germination and SVI upon ageing treatment. Reduction in TTC positively related with SVI (Fig. 2) indicating longer the viability of seed, greater the vigor index. Variation in seed germination and seedling vigor across the rice genotypes upon ageing treatment was demonstrated by Nisarga et al., (2017).

There is a significant increase in production of cytotoxic compounds (MDA, MG, amadori product) in aged seeds. Amongst the genotypes, SB3 showed less accumulation of MDA followed by SB15 compared to KCG6 (Table 2). The extent of accumulation of MDA negatively correlates with seed viability (Fig. 3a), germination (Fig. 3d) and seedling vigor index (Fig. 3g). Early loss of seed viability seeds upon ageing could be due to lipid peroxidation and loss of membrane phospholipids as they are considered to be the major cause of seed ageing (Priestley, 1986; Wilson and McDonald, 1986). Similarly, genotypes ICGV9114, KCG6 and VBT11 showed higher accumulation of $\mathrm{MG}$ and Amodari products (Glycation End Product) compared to other genotypes (Table 3) and showed negative effect on seed viability (Fig. $3 \mathrm{~b}$ and $3 \mathrm{c}$ ) and germination (Fig. 3e and 3f) that also negatively effects seedling vigor index (Fig. 3h and 3i). During accelerated ageing, cytotoxic compounds like melondialdehyde, methyl glyoxal, amadori products increased with time via lipid peroxidation and glycation which results in loss in germinability (Wettlluffer and Leopard, 1991). Therefore, reduction of such cytotoxic compounds is necessary for improved seed germination in seeds. Negative relationship between cytotoxic compounds and seed viability clearly indicates that, if the 
seeds remain to be viable and protect their germination ability, they need to keep cytotoxic compounds low. Accordingly, the genotypes which showed higher seed viability had least cytotoxic compound. The contrasting genotypes were identified based on the extent of cytotoxic accumulated and seed viability (reduction in TTC) as well as germination and SVI upon ageing treatment (Fig. 4). Genotypes SB3 and SB15 which showed longer seed viability that accumulated less cytotoxic compounds, and KCG6 and ICGV9114 has shorter seed viability with significantly higher levels of cytotoxic compounds upon ageing treatment were selected for gene expression studies

Table.1 Variation in seed viability, seed germination and seedling vigor index (SVI) across groundnut genotype under aged and non-aged condition

\begin{tabular}{|c|c|c|c|c|c|c|}
\hline \multirow[b]{2}{*}{ Genotypes } & \multicolumn{2}{|c|}{ Seed germination $(\%)$} & \multicolumn{2}{|c|}{$\begin{array}{l}\text { Seed viability (TTC } \\
\text { reduction) (OD @ 485nm) }\end{array}$} & \multicolumn{2}{|c|}{ Seedling Vigor Index (SVI) } \\
\hline & Control & 6 days AA & Control & 6 days AA & Control & 6 days AA \\
\hline SB1 & 93 & 73 & 1.08 & 0.81 & 3062.3 & 1271.0 \\
\hline SB2 & 100 & 70 & 1.38 & 0.81 & 3665.7 & 1675.7 \\
\hline SB3 & 100 & 80 & 1.31 & 1.15 & 4181.0 & 2185.7 \\
\hline SB7 & 93 & 70 & 1.07 & 0.75 & 3118.0 & 1252.0 \\
\hline SB8 & 93 & 70 & 1.13 & 0.82 & 3550.0 & 2405.7 \\
\hline SB10 & 97 & 70 & 1.30 & 0.87 & 3133.7 & 2031.0 \\
\hline SB11 & 97 & 73 & 1.17 & 0.88 & 3443.3 & 1655.3 \\
\hline SB12 & & 73 & 1.10 & 0.91 & 3209.0 & 1781.3 \\
\hline SB13 & 97 & 73 & 1.28 & 0.91 & 2674.3 & 2231.3 \\
\hline SB14 & 100 & 73 & 1.22 & 0.88 & 3093.7 & 1827.0 \\
\hline SB15 & 97 & 77 & 1.40 & 1.13 & 3934.7 & 1309.0 \\
\hline SB16 & 100 & 67 & 1.22 & 0.79 & 3296.7 & 1199.3 \\
\hline SB17 & 90 & 67 & 1.20 & 0.71 & 3539.3 & 1092.0 \\
\hline SB21 & 93 & 67 & 1.23 & 0.73 & 3141.0 & 1361.7 \\
\hline VB1 & 97 & 77 & 1.08 & 0.76 & 3248.3 & 1456.7 \\
\hline VB3 & 100 & 70 & 1.30 & 0.85 & 3422.7 & 1506.7 \\
\hline VB4 & 97 & 73 & 1.33 & 1.00 & 2692.7 & 1800.0 \\
\hline VB11 & 97 & 73 & 1.30 & 0.83 & 2527.3 & 2197.7 \\
\hline ICG9114 & 90 & 67 & 1.28 & 0.61 & 3644.0 & 712.0 \\
\hline KCG & 97 & 63 & 1.25 & 0.56 & 3508.0 & 888.0 \\
\hline \multicolumn{7}{|c|}{$\mathrm{CD} @ \mathrm{P}=\mathbf{0 . 0 5 \%}$} \\
\hline Genotype & \multicolumn{2}{|c|}{ NS } & \multicolumn{2}{|c|}{$0.17 * *$} & \multicolumn{2}{|c|}{ NS } \\
\hline treatment & \multicolumn{2}{|c|}{$2.58 * *$} & \multicolumn{2}{|c|}{$0.05^{*}$} & \multicolumn{2}{|c|}{$208.31 *$} \\
\hline G*T & \multicolumn{2}{|c|}{ NS } & \multicolumn{2}{|c|}{ NS } & \multicolumn{2}{|c|}{$931.65^{* *}$} \\
\hline
\end{tabular}


Table.2 Variation in accumulation of cytotoxic compound in accelerated aged and non-aged groundnut seeds

\begin{tabular}{|c|c|c|c|c|c|c|}
\hline \multirow[b]{2}{*}{ Genotypes } & \multicolumn{2}{|c|}{$\begin{array}{l}\text { MDA content } \\
(\mu \mathrm{M} / \mathrm{g} \text { FW })\end{array}$} & \multicolumn{2}{|c|}{$\begin{array}{l}\text { MG content } \\
(\mu \mathrm{M} / \mathrm{g} \text { FW })\end{array}$} & \multicolumn{2}{|c|}{$\begin{array}{l}\text { Amadori product } \\
(\mu \mathrm{M} / \mathrm{g} F W)\end{array}$} \\
\hline & Control & 6 days $\mathrm{AA}$ & Control & 6 days AA & Control & 6 days $\mathrm{AA}$ \\
\hline SB1 & 11.5 & 22.6 & 15.2 & 30.0 & 0.20 & 0.33 \\
\hline SB2 & 11.0 & 18.3 & 14.6 & 25.6 & 0.18 & 0.36 \\
\hline SB3 & 10.9 & 13.7 & 16.9 & 19.8 & 0.16 & 0.25 \\
\hline SB7 & 11.2 & 22.0 & 17.3 & 29.2 & 0.15 & 0.35 \\
\hline SB8 & 11.7 & 20.2 & 12.0 & 27.2 & 0.15 & 0.29 \\
\hline SB10 & 11.1 & 20.4 & 18.2 & 37.2 & 0.17 & 0.37 \\
\hline SB11 & 11.3 & 21.3 & 18.4 & 26.8 & 0.16 & 0.38 \\
\hline SB12 & 11.8 & 19.5 & 15.2 & 28.9 & 0.16 & 0.34 \\
\hline SB13 & 11.6 & 23.1 & 15.8 & 30.2 & 0.16 & 0.38 \\
\hline SB14 & 11.6 & 19.9 & 16.9 & 26.8 & 0.16 & 0.37 \\
\hline SB15 & 11.2 & 14.0 & 18.1 & 25.1 & 0.13 & 0.32 \\
\hline SB16 & 11.0 & 21.4 & 18.4 & 27.5 & 0.14 & 0.33 \\
\hline SB17 & 11.8 & 19.7 & 19.8 & 30.9 & 0.16 & 0.37 \\
\hline SB21 & 11.1 & 22.5 & 16.2 & 28.1 & 0.10 & 0.34 \\
\hline VB1 & 11.9 & 23.6 & 16.0 & 30.6 & 0.11 & 0.34 \\
\hline VB3 & 11.7 & 22.2 & 18.8 & 24.1 & 0.09 & 0.27 \\
\hline VB4 & 11.5 & 20.9 & 19.6 & 28.7 & 0.11 & 0.35 \\
\hline VB11 & 11.8 & 22.7 & 16.0 & 27.3 & 0.14 & 0.41 \\
\hline ICG9114 & 11.1 & 32.4 & 19.6 & 47.1 & 0.17 & 0.47 \\
\hline KCG & 11.6 & 26.5 & 19.4 & 45.0 & 0.19 & 0.46 \\
\hline \multicolumn{7}{|c|}{$\mathrm{CD} @ \mathrm{P}=\mathbf{0 . 0 5 \%}$} \\
\hline Genotype & \multicolumn{2}{|c|}{$2.65 * *$} & \multicolumn{2}{|c|}{ NS } & \multicolumn{2}{|c|}{$0.06 * *$} \\
\hline treatment & \multicolumn{2}{|c|}{$0.83 * *$} & \multicolumn{2}{|c|}{$2.73 * *$} & \multicolumn{2}{|c|}{$0.01 * *$} \\
\hline G*T & \multicolumn{2}{|c|}{$3.75^{* *}$} & \multicolumn{2}{|c|}{ NS } & \multicolumn{2}{|c|}{ NA } \\
\hline
\end{tabular}


Fig.1 Standardization of incubation period for seed viability, germination and seedling vigor index (SVI) in groundnut upon accelerated
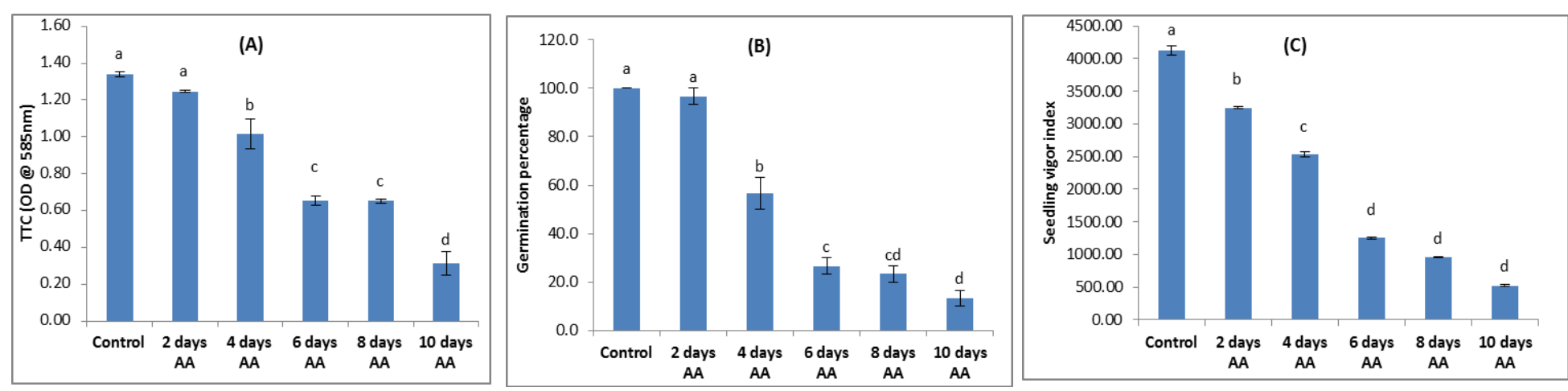

Fig.2 Relationship between seed viability and seedling vigor index (SVI) in groundnut upon accelerated aging (AA)

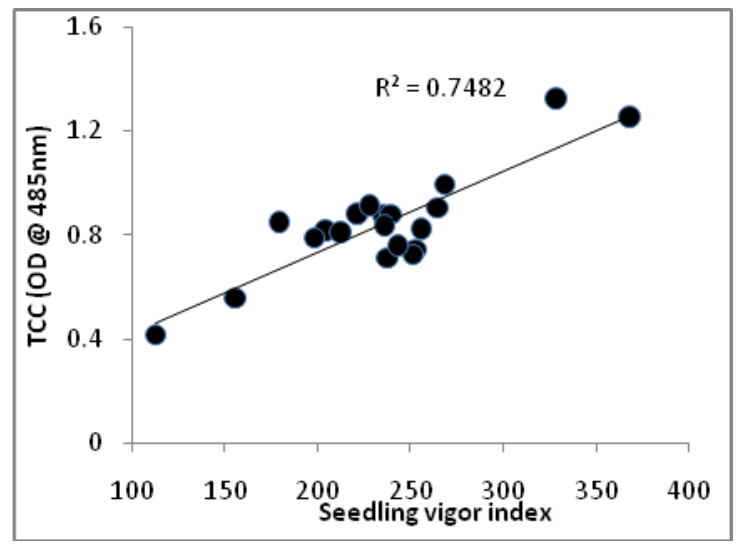


Fig.3 Accumulation of cytotoxic compounds affects seed viability, germination and seedling vigour (SVI) under accelerated ageing (AA)
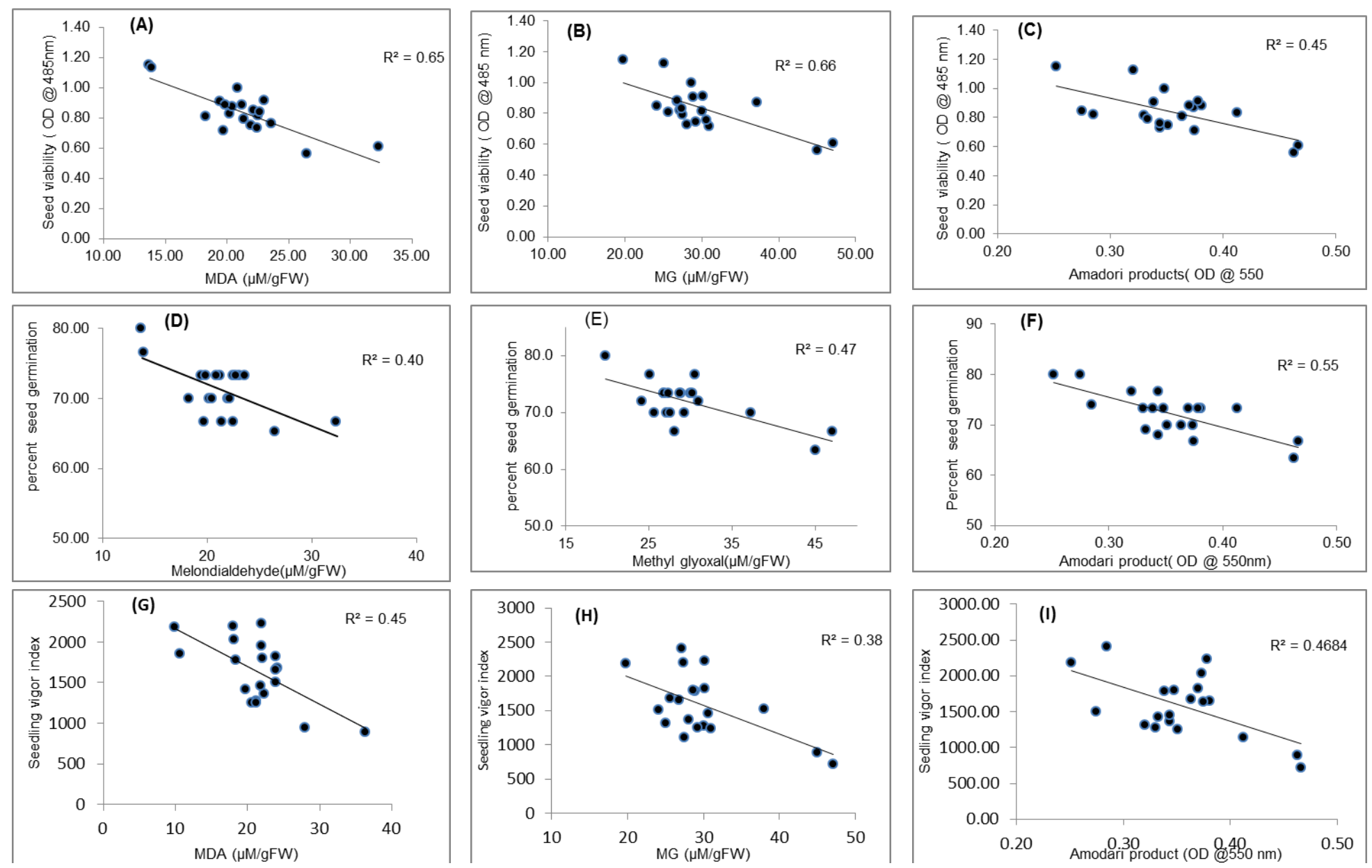
Fig.4 TTC staining (Fig. 4A) and seedling vigor index (Fig. 4B) in contrasting groundnut genotypes subjected to accelerated ageing (AA) treatment

(A)
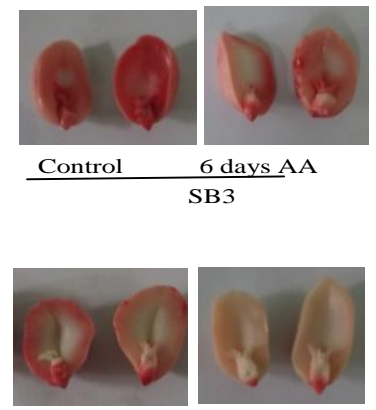

Control 6 days AA SB 15
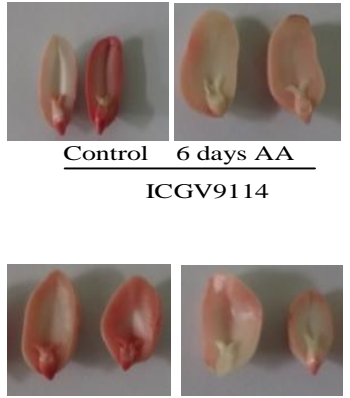

Control 6 days AA
(B)

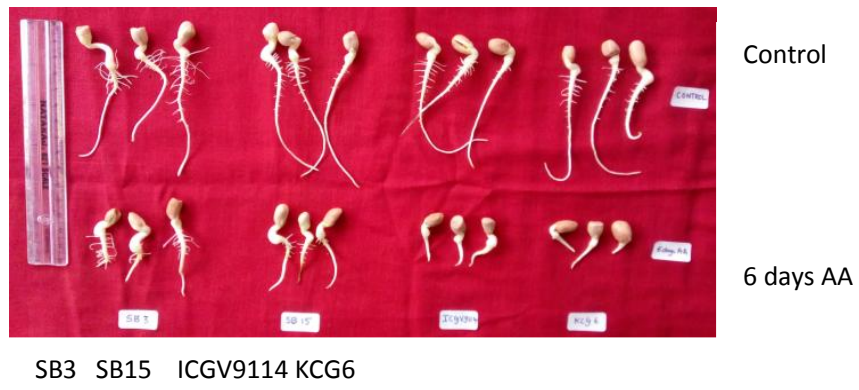

Fig.5 Expression of downstream target genes in contrasting groundnut genotypes upon accelerated ageing (AA) treatment

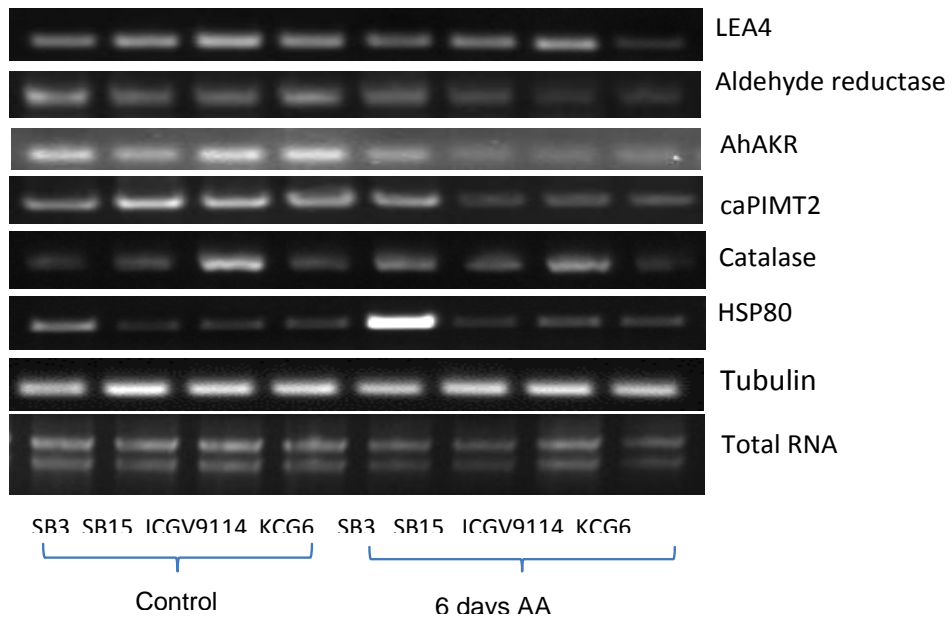

To assess the mechanisms associated for variability in genotypes that accumulated differential levels of cytotoxic compounds, the expression of few genes were studied. The genes that are involved in detoxification of RCC and ROS such as Aldo-ketoreductases (AKR1, Aldehyde reductase) (Oberschall et al., 2000), catalase (scavenger of $\mathrm{H}_{2} \mathrm{O}_{2}$ ) (Mittler et al., 2011) genes involved in protein stability [late embryogenic abundant (LEA4)] (Berjak et al., 1997), heat shock protein 80 (HSP80)], Aldehyde reductase (Mano et al., 2005) and Protein L-iso-aspartyl methyl transferase 1 (PIMT1) (Verma et al., 2013) that is involved in protein inactivation were assessed in contrasting ground genotypes upon ageing treatment. The expression of all these genes was down regulated under ageing treatments (Fig. 5). The expression of HSP80 was enhanced in genotype SB3 under ageing treatment. Similarly, upon ageing expression level of LEA4, Aldehyde reductase and AhAKR1 were more in tolerant genotypes than the susceptible genotype (Fig. 5). The expression of all these genes was significantly reduced in genotype KCG6 under ageing treatment. Overall the transcript levels in all genes were reduced in ageing treatment. 
In conclusion, the result of the study indicates, accelerated aging hasten up the ageing process in groundnut by increases the accumulation of cytotoxic compounds. Genetic variability for seed viability, seedling vigor and accumulation of cytotoxic compounds was observed across groundnut genotypes upon ageing treatment. Based on the levels of accumulation of cytotoxic compounds and seed viability, the contrasting genotypes were identified. Accordingly, some of the genotypes namely KCG6 and ICGV9114 were found to be susceptible to aging treatment, as they showed very less seed viability, germination percentage and accumulate higher cytotoxic compounds resulting in early loss of vigor, whereas, genotypes like SB3 and SB15 found to have high seed viability, germination with low level of cytotoxic compounds. Further, the correlation study suggest, there is inverse relationship between cytotoxic compounds accumulation and seed viability. As the cytotoxic compounds level increases, seed viability as well as seed germination decreases. Further, gene expression study confirms the role of downstream target in seed viability.

\section{References}

Abdul-Baki, A. A., and Anderson, J. D. 1973.Vigour determination in soybean by multiple criteria. Crop Sci., 10: 3134.

Asada, K. 2006. Production and Scavenging of Reactive Oxygen Species in Chloroplasts and Their Functions. Plant Physiol., 141(2): 391-396.

Bailly, C., and Kranner, I. 2011. Analyses of reactive oxygen species and antioxidants in relation to seed longevity and germination. Methods Mol. Biol., 773: 343-367.

Berjak, P., and Parmenter, N. W. 1997. Progress in understanding and manipulation of desiccation-sensitive (recalcitrant) seeds. Basic and Applied Aspects of Seed Biology, 22: 689-703.

Bewleyl, J. D., and Black, 1994.Seed Germination and Dormancy. The Plant Cell, 9: 1055-1066.

Datta, K,,Schimidt, A., and Marcus, A. 1989. Characterization of two soyabean repetitive proline-rich proteins and a cognate cDNA from germinated axes. Plant Cell, 1: 945-952.

Delouche, J. C., and Baskin, C. C. 1973. Accelerated aging techniques for predicting the relative storability of seed lots. Seed Sci. Technol. 1: 427452.

Ellis, R. H., and Filho, P. C. 1992. Seed development and cereal seed longevity. Seed Sci. Res., 2: 9-15.

Foyer, C. H., and Noctor, G. 2003. Redox sensing and signaling associated with reactive oxygen in chloroplasts, peroxisomes and mitochondria. Physiol. Plant, 119: 355-364.

Yin, J. J., Loa, F., Fu, P. P.,Wamer, W. J., Zhao, Y., Wang, P. C., Qiu, Y., Sun, B., Xing, G., Dong, J., Liang, X. J. and Chen, C. 2009. The scavenging of reactive oxygen species and the potential for cell protection by functionalized fullerene materials. Biomaterials, 30(4): 611-621.

Mano, J. 2012. Reactive carbonyl species: Their production from lipid peroxides, action in environmental stress, and the detoxification mechanism. Plant physiology and Biochemistry, 59: 9097.

Mano, J., Belles-Boix, E., Babiychuk, E., Inze, D., Torii, Y., Hiraoka, E. Takimoto, K. Slooten, L., Asada, K., and Kushnir, S. 2005. Protection against photo oxidative injury of tobacco leaves by 2-alkenal reductase and detoxification of lipid peroxidederived reactive carbonyls. Plant 
Physiol., 139: 1773-1783.

McDonalD, M. B. 1999. Seed deterioration:

Physiology, repair and assessment. Seed Science and Technology, 27(1): 177-237.

Mittler, R., Vanderauwera, S., Suzuki, N., Miller, G., Tognetti, V. B., Vandepoele, K., Gollery, M., Shulaev, V., and Vanbreusegem, F. 2011. ROS signaling: the new wave? Trends Plant Sci., 16: 300-309.

Nisarga, K. N., Ramu, S. V., Babitha, K. C., Hanumantha, R., Amaranatha Reddy, V., Ashwini, N., Udayakumar, M., Mohan Raju, B. 2017. Aldoketoreductase 1 (AKR1) improves seed longevity in tobacco and rice by detoxifying reactive cytotoxic compounds generated during ageing. Rice, 10: 11.

Oberschall, A., Deák, M., Török, K., Sass, L., Vass, I., Kovács, I., Fehér, A., Dudits, D., and Horváth, G. V. 2000. A novel aldose/aldehyde reductase protects transgenic plants against lipid peroxidation under chemical and drought stresses. Plant J., 24(4): 437446.
Priestley, D. A. 1986. Seed ageing. Publishing Associates Itheca New York, pp: 13755.

Roberts, E. H., and Ellis, R. H. 1989.Water and seed survival. Ann. Bot., 63: 3952.

Sung, J. M., and Jeng, T. L. 1994. Lipid peroxidation and peroxide-scavenging enzymes associated with accelerated ageing of peanut seed. Physiologia Plantarum, 91: 51-55.

Verma, P., Kaur, H., Petla, B. P., Rao, V., Saxena, S. C., and Majee, M. 2013. Protein L-Isoaspartyl Methyltransferase 2 is differentially expressed in chickpea and enhances seed vigour and longevity by reducing abnormal isoaspartyl accumulation predominantly in seed nuclear proteins. Plant Physiol., 161: 11411157.

Wettlaufer, S. H., and Leopold, A. C. 1991. Relevance of Amadori and Maillard products to seed deterioration. Plant Physiol. 97: 165-169.

Wilson, D. O., and McDonald, M. B. 1986. The lipid peroxidation model of seed ageing. Seed Sci. Technol., 14: 269300 .

\section{How to cite this article:}

Namratha, M.R., C.T. Bharath Prasad, Hajira Khanm and Mohan Raju, B. 2019. Genetic variability for Seed Viability, Seedling Vigor and Cytotoxic Compound Accumulation in Groundnut (Arachis hypogaea L.) upon Accelerated Ageing. Int.J.Curr.Microbiol.App.Sci. 8(02): 1817-1828. doi: https://doi.org/10.20546/ijcmas.2019.802.213 